\title{
The Connection between the Exchange Rate and the Balance of Payments Accounts in the Czech Republic: An Econometric Approach
}

\author{
Tomáš Urbanovský \\ Masaryk University \\ Faculty of Economics and Administration, Department of Finance \\ Lipová 507/41a, 60200 Brno, Czech Republic \\ E-mail: urbanovsky@mail.muni.cz
}

\begin{abstract}
Relationships between the nominal exchange rate, the current account and the financial account of the balance of payments in the Czech Republic are investigated in this presented paper. The implemented cointegration analysis and vector error correction model suggest one pair of Granger causality. It has been discovered that change in the current account balance Granger-causes a change in financial account balance. This relationship has the nature of two-way Granger causality, which means that a reversed relationship holds as well. Other relationships implying Granger causality were not found. Error terms were significant only in regressions with both accounts as dependent variables, which imply that only these variables return to their long-term equilibria. Because an increase in financial account surplus leads to a decrease in current account surplus (or deepening the current account deficit), excessive liberalization of the Czech financial system can lead to a large capital inflow, jeopardizes current account sustainability and results in a currency crisis in the Czech economy.
\end{abstract}

Keywords: exchange rate, balance of payments, cointegration, VECM

JEL codes: $C 32, C 51, F 32$

\section{Introduction}

Currency crises, sometimes known as balance of payments crises, are still a very real danger to market economies. The experience of currency crises indicates that a persistent current account deficit serves as a warning of an impending crisis. The aim of this paper is to find out whether the development of a nominal exchange rate and financial account affect the development of the current account in the Czech Republic or not. The proved existence of these relationships can be very important for the Czech monetary authority because a proper monetary policy can affect the development of the financial account and (or) nominal exchange rate, which can prevent an undesirable worsening of the current account (which can result in a currency crisis in the Czech Republic).

Because there are three variables, it is possible to find three potential relationships. The relationship between current and financial account proceeds from the balance of payments identity. According to the balance of payments identity, a country's current and financial account have to be balanced ex post, meaning that trade deficits (surpluses) will have to be accompanied by net capital inflows (outflows) of the same magnitude. Therefore, a negative correlation between the current and financial account must exist. However, the 
direction of causality is not clear at first sight and usually depends on the sample of countries under study (whether countries are developed or developing), as well as on the length of the period.

According to Oeking and Zwick (2015), the current account generally Grangercauses the financial account in OECD countries. However, for short-term flows, the direction changes over the business cycle: financial account components finance the current account during economic downturns while inducing its changes during upturns. In Yan (2005), Yan and Yang (2008) and Guerin (2004) Granger causality tests were implemented to find out that the financial account is responsible for the current account in developing countries - instead of financing the current account, the financial account thrusts the current account into an imbalance. Ersoy (2011) used Granger causality analysis under a VAR framework to reach the same conclusion for the Turkish economy - unidirectional causality runs from the financial account to the current account. Mastroyiannis (2012) examined the Portuguese economy and the implemented cointegration analysis suggests the existence of a long run relationship between foreign capital inflows and the current account position that is based upon a unidirectional causal long-run relationship, running from foreign capital inflows to current account position. He found a bidirectional relationship between the two variables in the short-run.

Nevertheless, Yan (2005) discovered a reversed relationship in developed countries - the financial account serves to finance a current account imbalance. Lau and Fu (2011) also observed that the current account Grangercauses the financial account suggesting that a current account can be used as the control policy variable for the flows of capital in the Asian countries of Indonesia, Korea, the Philippines and Thailand. The same conclusion can be found in Tang (2014) - this time for the US economy. And finally, Turan (2015) investigated the relationship between the current and financial account in several CEE countries, but results differ across the selected sample of countries.

Forogue and Veloce (1990) empirically proved the existence of bidirectional causality between the financial and the current accounts of Canada. Kim and Kim (2010) proved the same bidirectional causality for Korea. Fry et al. (1995) find that some developing countries have unidirectional, some have bidirectional and some have no causality between the financial and the current accounts.

Current account and nominal exchange rate are connected through international trade. Increased (decreased) exports will increase (decrease) the demand for the domestic currency, and, subsequently, cause an appreciation (depreciation) of the domestic currency. A second factor is imports development. Increased (decreased) imports will increase (decrease) the supply of the domestic currency, and, subsequently, cause a depreciation (appreciation) of the domestic currency. But again, the direction of causality is not clear at first sight - it is possible that the causality flows from the exchange rate to the components of the current account. Studies on the relationship between a current account and the nominal exchange rate are 
based on theoretical macroeconomic models elaborated mostly in the 1970s and 1980s. Dornbusch and Fischer (1980) suggest the existence of a causal relationship. In particular, that a current account is an important element in exchange rate determination. On the other hand, Martin (2016) used a panel of 180 countries over the 1960-2007 period and found evidence for a reversed relationship, which holds especially in non-industrial countries - flexible exchange rate arrangements deliver a faster current account adjustment. According to Larrain (2003), the relationship has the nature of a two-way causality. In particular, that exchange rate determines the current account, and the current account, in turn, determines the exchange rate.

A financial account and the nominal exchange rate are connected through capital flows. An inflow of foreign capital will increase the demand for domestic currency, and, subsequently, cause an appreciation of the domestic currency. An outflow of foreign capital will increase the supply of domestic currency, and, subsequently, cause a depreciation of the domestic currency. Again, the direction of causality can differ across the economies under study. Regarding the relationship between a financial account and the nominal exchange rate, Siourounis (2003) implemented an unrestricted VAR and found causality flowing from the financial account to the exchange rate in the UK, Germany, Switzerland and Japan. Gyntelberg et al. (2015) reached the same conclusion for the economy of Thailand. On the other hand, Kandil (2009) proved that fluctuations in the exchange rate are an important determinant of the financial balance in developing countries, but fluctuations in capital flows appear, in general, to be random in many developing and industrial countries, with limited evidence regarding the systematic correlation with exchange rate fluctuations.

Because of the reasons mentioned in the first paragraph of this section, the aim of this paper is to examine the nexus among the nominal exchange rate, and the current and financial account of balance of payments in the case of the Czech Republic. The rest of the paper is organized as follows. Section 2 covers a description of the data and relevant methodology. Section 3 presents the results of the analysis. Last section contains a summary and conclusions.

\section{Methodology and Data}

The presented analysis works with the above-mentioned macroeconomic variables: the nominal exchange rate, the current account and the financial account of the balance of payments. Data on each variable was acquired via the time series database ARAD administered by the Czech National Bank and processed in the econometric software Gretl. ARAD only contains data since 1995. Therefore, seasonally adjusted quarterly data on these variables for the Czech Republic from 1995Q1 to 2015Q4 is used, which means that 84 observations for each variable were collected from this period. Table 1 contains a short description of the variables and their abbreviations used in the analysis. 
Table 1 Variables used in the analysis

\begin{tabular}{cl}
\hline $\begin{array}{c}\text { abbreviation } \\
\text { of variable }\end{array}$ & \multicolumn{1}{c}{ variable characteristic } \\
\hline cur & current account balance expressed in millions of CZK \\
fin & financial account balance expressed in millions of CZK \\
rate & nominal exchange rate expressed as CZK/USD \\
\hline
\end{tabular}

Source: Author's work

It is possible that the exchange rate CZK/EUR would be more appropriate because Eurozone countries are the most important trade partners of the Czech Republic. Instead, CZK/USD was used and there are two main reasons for this decision:

- The euro came into existence on January 1,1999 , therefore, it is only possible to get 68 quarterly observations, which means a relatively short time series. This fact can lead to a potential robustness worsening of the empirical analysis.

- The current instability in the Eurozone (Brexit, the Greek crisis, the migration crisis, etc.) results in a high volatility of the euro. This volatility is independent of the situation of the Czech economy. With the use of CZK/EUR in the analysis, there would be the risk of an occurrence of no significant relationship between CZK/EUR and the macroeconomic indicators of the Czech Republic.

A typical characteristic for the time series is a correlation across the observations. Therefore, an appropriate number of lags for each variable needs to be determined to assess which data is independent. This step is crucial because, as soon as an autoregressive model of the appropriate order for each variable is found, it will be possible to test the (non)stationarity of variables. A sequential testing procedure is the most convenient way to determine the lag length for each variable. The chosen number of lags will be included in order to assess the intensity of the influence of previous values on the current value. Then lag lengths would be sequentially dropped if the relevant coefficients turn out to be statistically insignificant.

Because the model works with quarterly data, it is reasonable to suspect that the value of the variable from the same period a year before can help explain the value in the current period (i.e. the value in the second quarter of 2012 can explain the value in the second quarter of 2013, etc.). For this reason, the highest number of lags is set at four. After omitting insignificant lags, this final regression will be known as the autoregressive model of order $p(\operatorname{AR}(p)$ model) and because three variables are considered in the analysis, there will be three equations. The $\operatorname{AR}(p)$ model can be expressed more formally as: 
$X_{t}=\alpha+\sum_{i=1}^{p} \phi_{i} X_{t-i}+\varepsilon_{t}$

where $X_{t}$ represents the corresponding variable.

A crucial characteristic of a non-stationary time series is the presence of a unit root. The presence of a unit root is demonstrated by the coefficient $\phi_{1}$ equal to the unity in equation (1). However, for testing unit root behaviour, it is convenient to subtract $X_{t-1}$ from both sides of the equation (1). Formally:

$\Delta X_{t}=\alpha+\rho X_{t-1}+\sum_{i=1}^{p} \gamma_{i} \Delta X_{t-i}+\varepsilon_{t}$

where $\rho=\varphi-1 . \rho=0$ implies that the original time series, in the form of $A R(p)$, contains the unit root and is non-stationary. A test performed by means of equation (2) is called an augmented Dickey-Fuller test, invented in Dickey and Fuller (1979) - from now on it will be abbreviated as the ADF test.

Testing for the presence of unit roots in variables under study follows the procedure based on ADF tests. This procedure was originally developed by Dolado, Jenkinson and Sosvilla-Rivero (1990). The procedure used in this paper is a modification of this procedure done by Enders (2010). Because the actual data-generating process is not known, it seems reasonable to start testing the hypothesis $\rho=0$ using the general model, which also includes a time trend component. Formally:

$\Delta X_{t}=\alpha+\delta t+\rho X_{t-1}+\sum_{i=1}^{p} \gamma_{i} \Delta X_{t-i}+\varepsilon_{t}$

The ADF test is very popular. However, it is not sufficient to be interested only in (testing) the value of coefficient $\rho$, because results of ADF tests can be influenced by the statistical significance of a trend and (or) constant. For these reasons, joint hypotheses concerning $a, \delta$ and $\rho$ need to be tested. The whole testing procedure proceeds from equation (3) and has a complex multistage, in particular, see figure 1.

Please note that the original procedure covers all possible options an econometrician can encounter. The presented procedure, on the other hand, is simplified and is shadowing the outcomes of the model presented in the following section of paper (there is no need to present the whole procedure because all variables under study follow the same pattern, and some options of the original procedure are redundant for the purpose of this paper). Also note that in equations (3), (4) and (5), lag lengths discovered earlier in $\operatorname{AR}(p)$ processes are respected. 
Figure 1 The unit root testing procedure

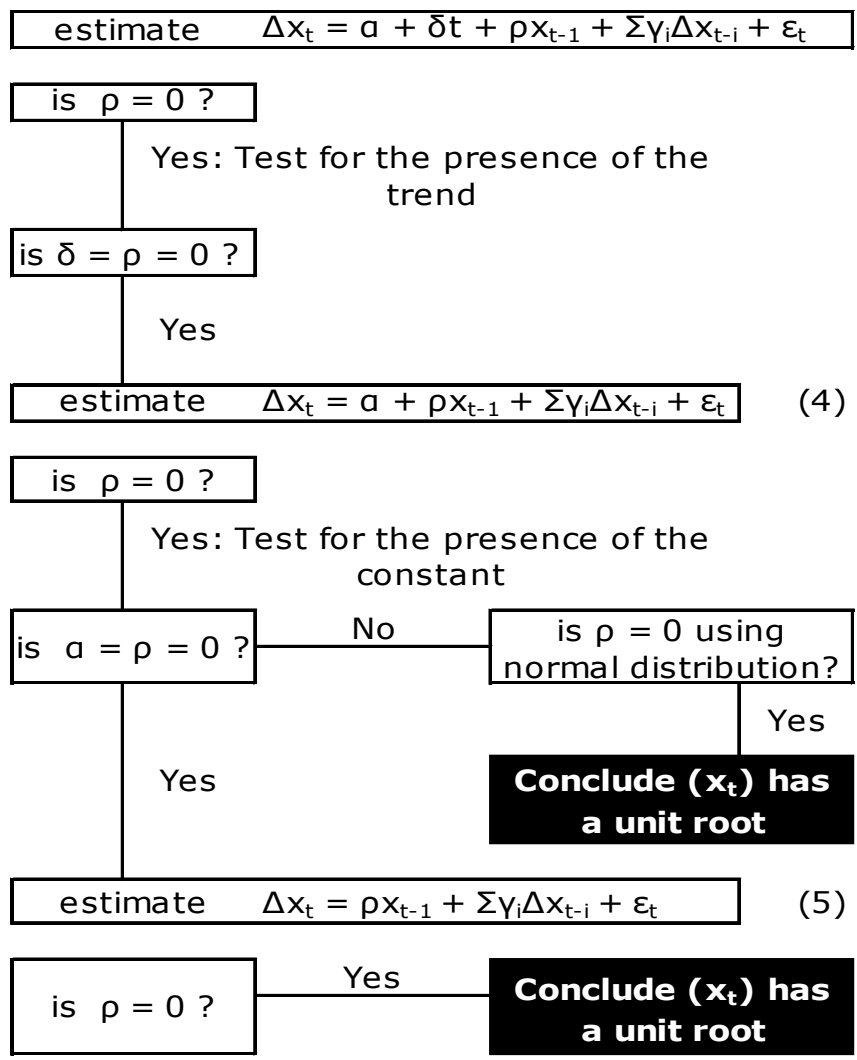

Source: Author's own elaboration based on Dolado, Jenkinson and Sosvilla-Rivero (1990) and Enders (2010)

\section{Model specification}

Previous studies showed that it is likely to find these variables to be nonstationary. Non-stationarity of all selected variables makes it possible to test the sample for the existence of cointegrating relationships among variables. Before proceeding to Johansen's cointegration test, developed in Johansen and Juselius (1990), it is necessary to find the appropriate number of lags for each variable. The highest number of lags is set at a level of four (for the same reason as discussed in the part of the paper dealing with the specification of AR processes). The decision of the most appropriate number of lags is based on information criteria - Akaike criterion (AIC) developed in Akaike (1974), Schwarz Bayesian criterion (BIC) developed in Schwarz (1978) and HannahQuinn criterion (HQC) developed in Hannah and Quinn (1979).

After the lag length determination, it is possible to perform Johansen's cointegration test to find out how many cointegrating relationships are present among the variables, i.e. to specify the cointegration rank. It was decided to 
use both a trace test and maximum eigenvalue test in order to find out whether the same conclusion would be reached or not.

Once the cointegration rank is determined, a short-term analysis in the form of a vector error correction model (VECM) can be performed. This particular model is convenient because it allows the identification of the patterns of Granger causality between variables. Furthermore, the inclusion of an error correction term (ECT) is crucial to determine whether variables displaying the previous period's deviation from long-run equilibrium are drawn back to their long-run equilibria or not. Formally, VECM can be written as:

$\Delta Y_{t}=\alpha+\sum_{i=1}^{p} \eta_{i} \Delta Y_{t-i}+\sum_{i=1}^{p} \zeta_{i} \Delta W_{t-i}+\sum_{i=1}^{p} \theta_{i} \Delta Z_{t-i}+\sum_{i=1}^{r} \lambda_{i} E C T_{t-i}+e_{t}$

To be more precise, this is only one of a total number of three equations, which together form VECM. These three equations differ in the dependent variable. Each equation regresses a dependent variable on the selected number of lags of all the variables in the VECM (the number of lags $p$ is determined by the information criteria). Only one equation is stated to save space. Note also that the number of ECTs depends on the cointegration rank $(r)$ - the number of cointegrating relationships is equal to the number of ECTs. The statistical significance of the corresponding coefficient implies Granger causality, meaning that a variable with this coefficient Granger-causes a dependent variable.

\section{Results and Discussion}

Simple OLS regressions were used to determine the order of $\operatorname{AR}(p)$ process for each variable under study in order to find out a potential correlation between the consecutive values of each variable. The results of the performed OLS regressions of variables under study on their lags are stated in Table 2 (only coefficient estimates and $p$-values are included in the table in order to save space). Please note that the expression $X$ in the first column always represents the lags of a corresponding dependent variable.

Regression results for variable cur and fin correspond with the assumption presented in the previous section of the paper. In particular that the value of a variable from the same period a year before can help explain the value in the current period. In the case of a variable rate, statistically insignificant lags were sequentially dropped from the regression in order to receive more accurate estimations of significant coefficients - these dropped lags are illustrated by blank spaces. It is obvious that the current value of the variable rate depends only on the instantly preceding value. 
Table 2 OLS regressions of variables under study on their lags

\begin{tabular}{|c|c|c|c|c|c|c|c|}
\hline \multirow{3}{*}{$\begin{array}{c}\text { explanatory } \\
\text { variables }\end{array}$} & \multicolumn{7}{|c|}{ dependent variable $\left(X_{t}\right)$} \\
\hline & \multicolumn{3}{|c|}{$\mathrm{cur}_{\mathrm{t}}$} & \multicolumn{2}{|c|}{ fin $_{\mathrm{t}}$} & \multicolumn{2}{|r|}{ rate $_{\mathrm{t}}$} \\
\hline & coef. & p-value & & coef. & p-value & coef. & p-value \\
\hline const. & -7601.44 & 0.1499 & & 868.712 & 0.8373 & 0.8089 & 0.2764 \\
\hline$X_{t-1}$ & 0.0012 & 0.9899 & & 0.0926 & 0.3081 & 0.9680 & $2.36 \mathrm{e}-050 * * *$ \\
\hline$x_{t-2}$ & -0.1131 & 0.2256 & & 0.0498 & 0.5842 & & \\
\hline$x_{t-3}$ & 0.0548 & 0.5563 & & 0.06 & 0.4894 & & \\
\hline$\underline{X_{t-4}}$ & 0.6624 & $7.27 e-09$ & $* * *$ & 0.7149 & $6.00 \mathrm{e}-010 * * *$ & & \\
\hline $\mathrm{R}^{2}$ & \multicolumn{3}{|c|}{0.412094} & \multicolumn{2}{|c|}{0.420036} & \multicolumn{2}{|c|}{0.936856} \\
\hline adjusted $\mathrm{R}^{2}$ & \multicolumn{3}{|c|}{0.380739} & \multicolumn{2}{|c|}{0.389094} & \multicolumn{2}{|c|}{0.936077} \\
\hline P-value $(F)$ & \multicolumn{3}{|c|}{$3.68 e-08$} & \multicolumn{2}{|c|}{$2.25 e-08$} & \multicolumn{2}{|c|}{$2.36 e-50$} \\
\hline
\end{tabular}

Note: Significance at $* * * 1 \%$

Source: Author's own elaboration based on Gretl output and on data acquired via ARAD

Based on the results, it is possible to see that the best way to describe the behaviour of variable cur and fin is by means of $A R(4)$ processes and a variable rate by means of an $A R(1)$ process. Formally:

$$
\begin{aligned}
& \text { cur }_{t}=\alpha_{1}+\sum_{i=1}^{4} \phi_{i}^{\text {cur }} \text { cur }_{t-i}+\varepsilon_{t}^{\text {cur }} \text { fin }_{t}=\alpha_{2}+\sum_{i=1}^{4} \phi_{i}^{\text {fin }} \text { fin }_{t-i}+\varepsilon_{t}^{\text {fin }} \\
& \text { rate }_{t}=\alpha_{3}+\phi_{1}^{\text {rate }} \text { rate }_{t-1}+\varepsilon_{t}^{\text {rate }}
\end{aligned}
$$

After the specification of AR processes, it is possible to construct equations for ADF tests. This is achieved by the subtraction of the first lag of the dependent variable in each equation:

$$
\begin{aligned}
& \Delta \text { cur }_{t}=\alpha_{1}+\rho^{\text {cur }} \text { cur }_{t-1}+\sum_{i=1}^{3} \gamma_{i}^{\text {cur }} \Delta \text { cur }_{t-i}+\varepsilon_{t}^{c u r} \\
& \Delta \text { fin }_{t}=\alpha_{2}+\rho^{\text {fin }_{\text {fin }}+1}+\sum_{i=1}^{3} \gamma_{i}^{\text {fin }} \Delta \text { fin }_{t-i}+\varepsilon_{t}^{\text {fin }} \\
& \text { rrate }_{t}=\alpha_{3}+\rho^{\text {rate }} \text { rate }_{t-1}+\varepsilon_{t}^{\text {rate }}
\end{aligned}
$$

The next step is testing for the presence of unit roots. Testing follows the scheme mentioned in the previous section. The results of this procedure for each variable are stated in Appendix A (only characteristics crucial for deciding the existence of unit roots are stated). From t-statistics, it is obvious that coefficients $\rho$ are statistically insignificant in the cases of all variables, i.e. null hypotheses that they are equal to zero cannot be rejected. Therefore, the conclusion is that all original time series are first-order integrated or $I(1)$, which means every variable contains a unit root and displays non-stationary behaviour. 
All variables are non-stationary, therefore, testing for the existence of cointegration is desirable. The first step is to find an appropriate number of lags with the use of information criteria. The best option appears to be an option with one lag according to BIC and HQC (although AIC suggests the inclusion of four lags).

Table 3 Lag length determination

\begin{tabular}{lcccc}
\hline & lags 1 & lags 2 & lags 3 & lags 4 \\
\hline AIC & 50.290260 & 50.268223 & 50.440386 & $\mathbf{5 0 . 0 2 7 6 5 6}$ \\
BIC & $\mathbf{5 0 . 5 5 8 2 3 8}$ & 50.804179 & 51.244320 & 51.099568 \\
HQC & $\mathbf{5 0 . 3 9 7 7 0}$ & 50.483103 & 50.762706 & 50.457416
\end{tabular}

Source: Author's own elaboration based on Gretl output and on data acquired via ARAD

Now it is time to proceed to Johansen's cointegration test to find out how many cointegrating relationships are present among the variables, i.e. to specify the cointegration rank. The results are summarized in Table 4. According to the trace test, the null hypothesis of existence of two cointegrating relationships cannot be rejected. The same outcome is received with the usage of a maximum eigenvalue test. Therefore, both tests suggest that the subsequent short-term analysis should have the form of a VECM with a cointegration rank 2 .

Table 4 Rank determination (Johansen cointegration test)

\begin{tabular}{ccccc}
\hline $\begin{array}{c}\text { Null } \\
\text { Hypothesis }\end{array}$ & $\begin{array}{c}\text { Alternative } \\
\text { hypothesis }\end{array}$ & Eigenvalue & Test statistic & p-value \\
\hline \multicolumn{5}{c}{ Trace test } \\
\hline$r=0$ & $r>0$ & 0.52979 & 109.99 & 0.0000 \\
$r \leq 1$ & $r>1$ & 0.42579 & 47.363 & 0.0000 \\
$\mathbf{r} \leq \mathbf{2}$ & $\mathbf{r} \mathbf{2}$ & $\mathbf{0 . 0 1 5 7 4 8}$ & $\mathbf{1 . 3 1 7 5}$ & $\mathbf{0 . 2 5 1}$ \\
\hline$r=0$ & $r=1$ & 0.52979 & 62.63 & 0.0000 \\
$r=1$ & $r=2$ & 0.42579 & 46.045 & 0.0000 \\
$\mathbf{r}=\mathbf{2}$ & $\mathbf{r}=\mathbf{3}$ & $\mathbf{0 . 0 1 5 7 4 8}$ & $\mathbf{1 . 3 1 7 5}$ & $\mathbf{0 . 2 5 1}$
\end{tabular}

Source: Author's own elaboration based on Gretl output and on data acquired via ARAD

The outputs of the estimated VECM with a cointegration rank 2 are stated in Table 5. Note that the lag length established earlier is respected in the VECM analysis. Therefore, each variable is regressed on one lag of all variables under study plus two error correction terms (because two cointegrating relationships are present). Again, only coefficient estimates and $p$-values are included in the table in order to save space. 
Table 5 A VECM with a cointegration rank 2

\begin{tabular}{|c|c|c|c|c|c|c|c|c|}
\hline \multirow[t]{2}{*}{$\begin{array}{c}\text { explanatory } \\
\text { variables }\end{array}$} & \multicolumn{8}{|c|}{ dependent variable } \\
\hline & coef. & $p$-value & & coef. & $p$-value & & coef. & $\mathrm{p}$-value \\
\hline const. & -22319.0 & 0.0002 & $* * *$ & -675.78 & 0.9202 & & 0.0668 & 0.8498 \\
\hline$\Delta$ cur $_{\mathrm{t}-1}$ & 0.6744 & 0.0003 & $* * *$ & 0.6049 & 0.0051 & $* * *$ & $-9.09952 e-06$ & 0.4086 \\
\hline$\Delta \mathrm{fin}_{\mathrm{t}-1}$ & -0.4469 & 0.0059 & $* * *$ & -0.5268 & 0.0056 & $* * *$ & $6.43684 \mathrm{e}-06$ & 0.5070 \\
\hline$\Delta$ rate $_{\mathrm{t}-1}$ & 1011.49 & 0.6010 & & 2519.70 & 0.2673 & & -0.0300 & 0.7998 \\
\hline $\mathrm{ECT}_{\mathrm{t}-1}$ & -1.5895 & 0.0000 & $* * *$ & -0.4955 & 0.0959 & $*$ & $4.11315 \mathrm{e}-06$ & 0.7896 \\
\hline $\mathrm{ECT}_{\mathrm{t}-2}$ & -0.3614 & 0.0088 & $*$ & -0.4619 & 0.0634 & $*$ & $-3.48784 e-06$ & 0.7862 \\
\hline $\mathrm{R}^{2}$ & \multicolumn{3}{|c|}{0.586298} & \multicolumn{3}{|c|}{0.518505} & \multicolumn{2}{|c|}{0.013576} \\
\hline DW stat. & \multicolumn{3}{|c|}{2.034006} & \multicolumn{3}{|c|}{2.034319} & \multicolumn{2}{|c|}{2.006379} \\
\hline
\end{tabular}

Note: Significance at $* 10 \%, * * * 1 \%$

Source: Author's own elaboration based on Gretl output and on data acquired via ARAD

The first interesting finding is that two of three regressions display a relatively high value of determination coefficient $\left(R^{2}\right)$ - in the case of dependent variable $\Delta$ cur ${ }_{t}$, almost $59 \%$, which means that the given variables explain at $58.62 \%$ the variability of variable $\Delta c u r_{t}$. Only the equation with dependent variable

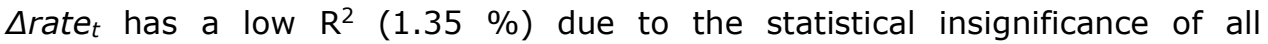
explanatory variables.

The last row represents the values of Durbin-Watson statistics. All values are relatively close to value 2 , which indicates the desirable property of regressions - no autocorrelation of residuals.

Looking at the regressions themselves reveals several facts. First of all, the lags of the dependent variables are statistically significant in regressions with $\Delta c u r_{t}$ and $\Delta f i n_{t}$ as dependent variables. It means that current changes in variables $\Delta c u r_{t}$ and $\Delta f i n_{t}$ can be explained by the previous changes of these variables. This is clearly not the case with dependent variable $\Delta$ rate $_{t}$ because the previous value of $\Delta$ rate $_{t}$ has no explanatory power.

Secondly, only one pattern of Granger causality is obvious from the table. In the equation with $\Delta c u r_{t}$ as the dependent variable, it is clear that past financial account balance change has an explanatory power for the current account balance change - in other words, past financial account balance change Granger-causes a current account balance change. And from looking at a regression with $\Delta$ fin $_{t}$ as the dependent variable, it is obvious that a reversed relationship exists - past current account balance change Granger-causes a financial account balance change. Because causality flows in both directions, two-way Granger causality exists between the current account and the financial account of the balance of payment. And because there is a negative sign in both cases (-0.4469 and -0.6049), a positive change of the explanatory variable is associated with a negative change of the dependent variable and vice versa. Specifically, an increase (decrease) in the financial account balance is linked to a worsening (improvement) of the current account balance, and an increase (decrease) in the current account balance is linked to a worsening (improvement) of the financial account balance. This is in accordance with the balance of payments identity mentioned in the first section of the paper. 
Finally, error correction terms are significant in two regressions, which correspond with the two previously discovered cointegrating relationships. Corresponding coefficients also have a negative sign, which is crucial for VECM. This necessity is demonstrated on the variable cur. If the error term in the previous period is positive (negative), the previous value of the variable cur is too high (low) to be in equilibrium. And because this positive (negative) error term will be multiplied by a negative coefficient, the product will be negative (positive) and the variable cur will start falling (rising) in the next period and the error will be corrected. The same holds for variable fin. This means that these two variables are drawn back to their equilibria. In other words, past equilibrium error is corrected in the model only in the cases of these two variables.

This reasoning does not hold in the case of a variable rate because error correction terms coefficients are not statistically significant. And what's more, exchange rate change not only does not have any explanatory power in regressions with $\Delta c u r_{t}$ and $\Delta f i n_{t}$ as dependent variables, but also $\Delta c u r_{t}$ and $\Delta f_{i n}$ cannot help explain an exchange rate change. It means that there is no connection between the exchange rate and these two accounts of the balance of payments. Therefore, changes in exchange rate should not affect the balance of payments development, and vice versa - exchange rate development should be independent of balance of payments development.

The main contribution of the presented empirical paper is that bidirectional causal relationship between a current and financial account has been proved in the case of the Czech Republic. Similar conclusions were reached by Forogue and Veloce (1990) for the Canadian economy and Kim and Kim (2010) for the Korean economy. Crucial is the situation when an increase in financial account surplus leads to a decrease in current account surplus (or deepening the current account deficit) because, as mentioned in the first section of this paper, a long-lasting current account deficit can result in a currency crisis. The final conclusion is that excessive liberalization of the Czech financial system can lead to a large capital inflow and put current account sustainability into jeopardy.

These findings from the presented empirical study complement current research studies on issues related to the interaction between financial account development and the adjustment of current account imbalance.

\section{Conclusions}

The relationships between three macroeconomic variables - the nominal exchange rate, the current account and the financial account of the balance of payments - in the Czech Republic were investigated in the presented paper. After a brief theoretical insight into this issue, data and the methodology used in subsequent analysis were introduced. Several facts have been found in the empirical part of the paper. ADF tests, performed after the determination of the order of AR processes, proved that each variable under study contains a unit root and, therefore, displays non-stationary behaviour. The subsequently performed Johansen's cointegration test suggests that two cointegrating 
relationships are present among the variables, which means that the resulting model took the form of a vector error correction model with a cointegration rank 2. The implemented VECM showed that two-way Granger causality exists between a current and financial account, in particular: an increase (decrease) in a current account balance leads to a decrease (increase) in a financial account, and vice versa. The statistical significance of error terms also suggest that these two variables return to their long-term equilibria. Because an increase in financial account surplus leads to a decrease in current account surplus, the main conclusion of the presented paper is that the excessive liberalization of the Czech financial system can lead to a large capital inflow, put current account sustainability into jeopardy and elicit a currency crisis in the Czech Republic.

\section{Acknowledgements}

The support of the Masaryk University internal grant MUNI/A/1039/2016 is gratefully acknowledged.

\section{References}

Akaike, H. (1974). A new look at the statistical model identification. IEEE Transactions on Automatic Control, 19(6), pp. 716-723.

Dickey, D. A. and Fuller, W. A. (1979). Distribution of estimators for time series regressions with a unit root. Journal of the American Statistical Association, 74, pp. 427-431.

Dolado, J., Jenkinson, T. and Sosvilla-Rivero, S. (1990). Cointegration and Unit Roots. Journal of Economic Surveys, 4(3), pp. 249-273.

Dornbusch, R. and Fischer, S. (1980). Exchange Rates and the Current Account. The American Economic Review, 70(5), pp. 960-971.

Enders, W. (2010). Applied econometric time series (3rd ed.). Hoboken: Wiley. Ersoy, I. (2011). The Causal Relationship between the Financial Account and the Current Account: The Case of Turkey. International Research Journal of Finance and Economics, 75, pp.187-193.

Faroque, A. and Veloce, W. (1990). Causality and Structure of Canada's Balance of Payments. Empirical Economics, 15, pp. 267-283.

Fry, M., Claessens, S., Burridge, P. and Blanchet, M-C. (1995). Foreign Direct Investment, Other Capital Flows and Current Account Deficit: What causes what? World Bank Policy Research Working Paper, no.1527.

Guerin, S. S. (2004). The relationship between capital flows and current account: volatility and causality. ECARES, Université Libre de Bruxelles.

Gyntelberg, J., Loretan, M. and Subhanij, T. (2015). Private information, capital flows, and exchange rates. Swiss National Bank: Working paper, no. 12.

Hannan, E. J. and Quinn, B. G. (1979). The Determination of the order of an autoregression. Journal of the Royal Statistical Society, Series B, 41, pp. 190195. 
Johansen, S. and Juselius, K. (1990). Maximum Likelihood Estimation and Inference on Cointegration - with Applications to the Demand for Money. Oxford Bulletin of Economics and Statistics, 52, pp. 169-210.

Kandil, M. (2009). Exchange Rate Fluctuations and the Balance of Payments: Channels of Interaction in Developing and Developed Countries. Journal of Economic Integration, 24(1), pp. 151-174.

Kim, C.-H. and Kim, D. (2010). Do Capital Inflows cause Current Account Deficits? Applied Economics Letters, 18(5), pp. 497-500.

Larrain, M. (2003). Central bank intervention, the current account, and exchange rates. International Advances in Economic Research, 9(3), pp. 196205.

Lau, E. and Fu, N. (2011). Financial and current account interrelationship: An empirical test. Journal of Applied Economic Sciences, 6(1), p. 34-42.

Martin, F. E. (2016). Exchange rate regimes and current account adjustment: An empirical investigation. Journal of International Money and Finance, 65, pp. 69-93.

Mastroyiannis, A. (2012). Causality Relationships in the Structure of Portugal's Balance of International Payments. International Journal of Business and Social Science, 3(15), pp. 54-61.

Oeking, A. and Zwick, L. (2005). On the Relation between Capital Flows and the Current Account. Ruhr Economic Papers \#565.

Schwarz, G. E. (1978). Estimating the dimension of a model. Annals of Statistics, 6(2), pp. 461-464.

Siourounis, G. (2003). Capital Flows and Exchange Rates: An Empirical Analysis. London Business School, IFA Working Paper, No. 400.

Tang, T. C. (2014). Fiscal Deficit, Trade Deficit, and Financial Account Deficit: Triple Deficits Hypothesis with the U.S. Experience. Monash University Malaysia: DISCUSSION PAPER, vol. 6.

Turan, T. (2015). Causal relationship between current account and financial account balance in selected CEE countries. Journal of Economics, 63(9), pp. 959-974.

Yan, H. and Yang, C. (2008). Foreign Capital Inflows and the Current Account Imbalance: Which Causality Direction? Journal of Economic Integration, 23(2), pp. 434-461.

Yan, H.-D. (2005). Causal Relationship between the Current Account and Financial Account. International Advances in Economic Research, 11(2), pp. 149-162. 


\section{Appendix A: Testing for the presence of a unit root}

- variable cur

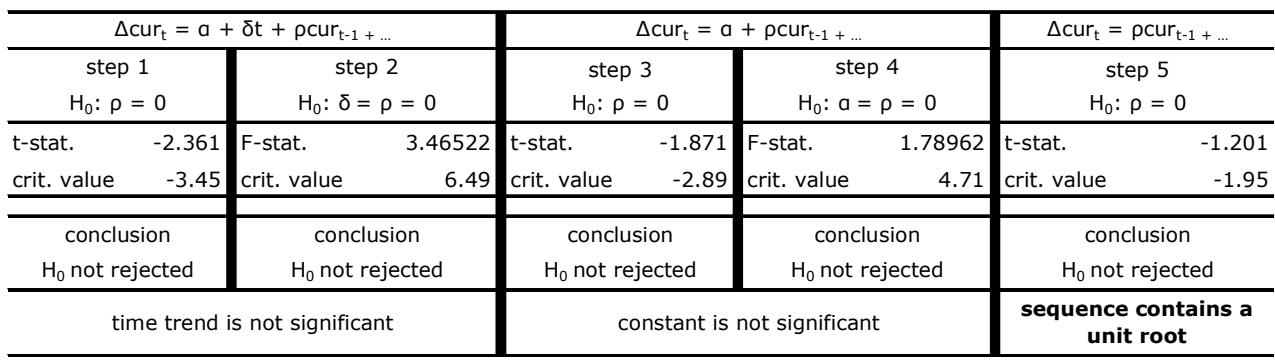

Source: Author's own elaboration based on Gretl output and on data acquired via ARAD

- $\quad$ variable fin

\begin{tabular}{|c|c|c|c|c|c|c|c|c|c|}
\hline \multicolumn{4}{|c|}{$\Delta \mathrm{fin}_{\mathrm{t}}=\mathrm{a}+\delta \mathrm{t}+\rho \mathrm{fin}_{\mathrm{t}-1+\ldots}$} & \multicolumn{4}{|c|}{$\Delta$ fin $_{t}=a+\rho f i n_{t-1+\ldots}$} & \multicolumn{2}{|c|}{$\Delta$ fin $_{t}=\rho$ fin $_{t-1}+\ldots$} \\
\hline \multirow{2}{*}{\multicolumn{2}{|c|}{$\begin{array}{c}\text { step } 1 \\
\mathrm{H}_{0}: \rho=0\end{array}$}} & \multirow{2}{*}{\multicolumn{2}{|c|}{$\begin{array}{c}\text { step } 2 \\
\mathrm{H}_{0}: \delta=\rho=0\end{array}$}} & \multirow{2}{*}{\multicolumn{2}{|c|}{$\begin{array}{c}\text { step } 3 \\
\mathrm{H}_{0}: \rho=0\end{array}$}} & \multirow{2}{*}{\multicolumn{2}{|c|}{$\begin{array}{c}\text { step } 4 \\
\mathrm{H}_{0}: a=\rho=0\end{array}$}} & \multirow{2}{*}{\multicolumn{2}{|c|}{$\begin{array}{c}\text { step } 5 \\
\mathrm{H}_{0}: \rho=0\end{array}$}} \\
\hline & & & & & & & & & \\
\hline t-stat. & -1.589 & F-stat. & 2.88899 & t-stat. & -0.4679 & F-stat. & 0.352421 & t-stat. & -0.819 \\
\hline crit. value & -3.45 & crit. value & 6.49 & crit. value & -2.89 & crit. value & 4.71 & crit. value & -1.95 \\
\hline \multicolumn{2}{|c|}{ conclusion } & \multicolumn{2}{|c|}{ conclusion } & \multicolumn{2}{|c|}{ conclusion } & \multicolumn{2}{|c|}{ conclusion } & \multicolumn{2}{|c|}{ conclusion } \\
\hline \multicolumn{2}{|c|}{$\mathrm{H}_{0}$ not rejected } & \multicolumn{2}{|c|}{$\mathrm{H}_{0}$ not rejected } & $\mathrm{H}_{0}$ not & ected & \multicolumn{2}{|c|}{$\mathrm{H}_{0}$ not rejected } & \multicolumn{2}{|c|}{$\mathrm{H}_{0}$ not rejected } \\
\hline \multicolumn{4}{|c|}{ time trend is not significant } & \multicolumn{4}{|c|}{ constant is not significant } & \multicolumn{2}{|c|}{$\begin{array}{c}\text { sequence contains a } \\
\text { unit root }\end{array}$} \\
\hline
\end{tabular}

Source: Author's own elaboration based on Gretl output and on data acquired via ARAD

- variable rate

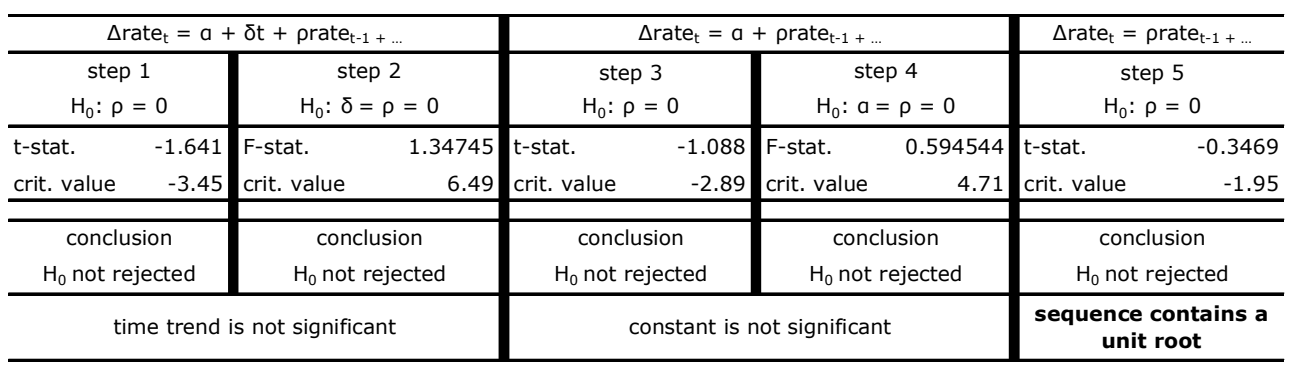

Source: Author's own elaboration based on Gretl output and on data acquired via ARAD 